\title{
First in vivo study shows optical imaging can distinguish renal cancer from normal tissue
}

Optical coherence tomography (OCT) is a high-resolution light-based technique widely used in ophthalmology to image the retina in real time. Researchers in The Netherlands have transferred this technique to the human kidney, and now they report the first in vivo study of OCT for renal tumours in BJU International. Their finding that OCT can accurately differentiate between malignant renal tissue and normal parenchyma suggests that OCT might prove to be a reliable, minimally invasive alternative to biopsy for the diagnosis of kidney cancer. "One of the major reasons that a renal mass biopsy is not included in the standard diagnostic workup is the high number of nondiagnostic biopsy results-about 20\% in most contemporary studies," says Kurdo Barwari, lead author of the study.

Kidney tissue was obtained from 16 patients who underwent nephrectomy (radical or partial) or laparoscopic cryoablation for a solid enhancing renal mass. OCT was performed during surgery to obtain in vivo images of both the mass and normal renal parenchyma, and the attenuation of light per millimeter of tissue was quantified as an attenuation coefficient $\left(\mu_{\mathrm{OCT}}\right)$. "Our hypothesis was that a higher degree of light scattering in malignant tissue would result in a higher $\mu_{\text {OCT }}$ compared to normal or benign tissue," says Barwari.

Indeed the investigators did find that $\mu_{\mathrm{OCT}}$ was significantly higher in malignant renal tissue (median $\mu_{\text {OCT }} 9.2 \mathrm{~mm}^{-1}$ in samples from 11 patients with renal cell

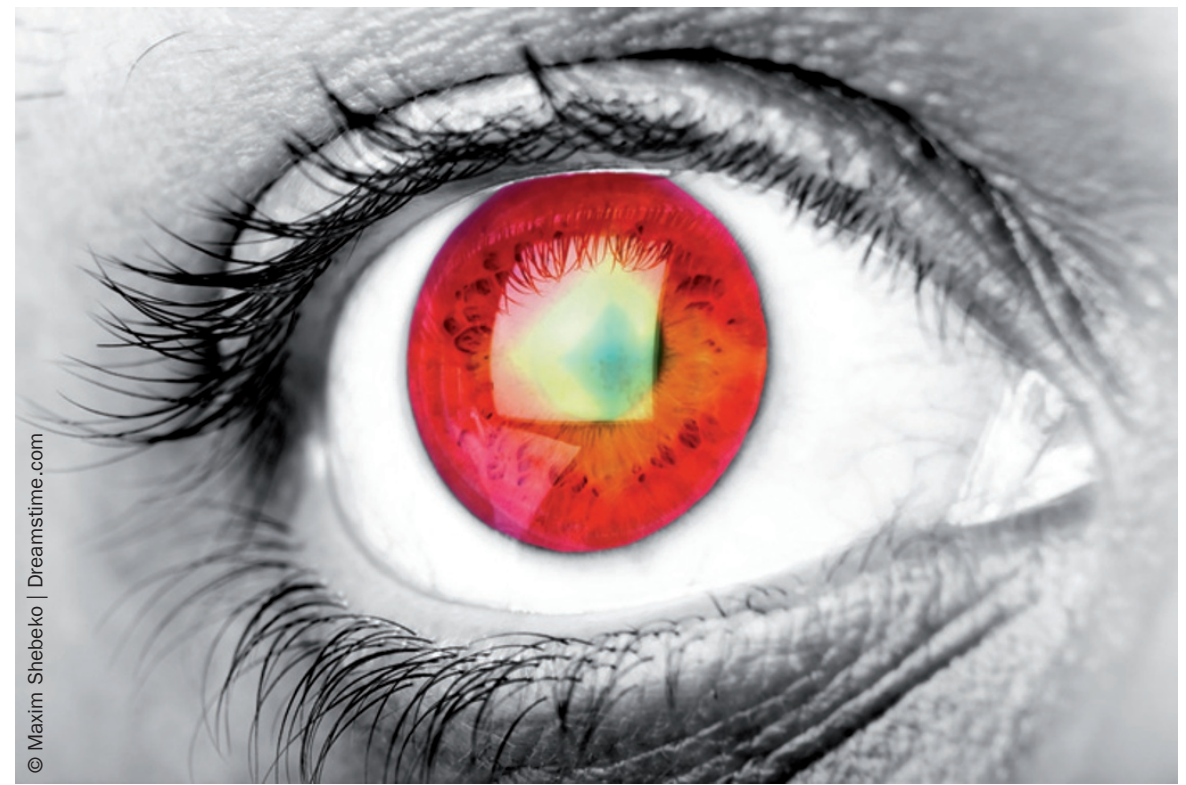

carcinoma) than in normal parenchyma (median $\mu_{\mathrm{OCT}} 5.0 \mathrm{~mm}^{-1}$ in samples from all 16 patients; $P<0.001$ ). Unfortunately, a low number of benign tumours in the study cohort $(n=3)$ meant that conclusions could not be made concerning the ability of OCT to differentiate between benign tissue and either normal parenchyma or malignant tumours.

Barwari and colleagues support their promising data with an explanation of the advantages of OCT-light-based techniques are harmless to human tissue, provide real-time information, and can be miniaturized, allowing integration with existing clinical procedures. "We are currently designing a multicentre study to expand the patient population and demonstrate the discriminative ability of OCT with more power. When validated, we can assess the ability of OCT to identify renal tumours in a clinical setting, for example with OCT-guided renal mass biopsy or real-time surgical margin assessment during partial nephrectomy," Barwari concludes.

Sarah Payton

Original article Barwari, K. et al. Differentiation between normal renal tissue and renal tumours using functional optical coherence tomography: phase I in vivo human study. BJU Int. doi:10.1111/j.1464-410X.2012.11197.x. 